http://jmscr.igmpublication.org/home/

ISSN (e)-2347-176x ISSN (p) 2455-0450

crossref DOI: https://dx.doi.org/10.18535/jmscr/v7i7.98

Journal Of Medical Science And Clinical Research

IGM Publication

An Official Publication of IGM Publication

\title{
Comparison of intraocular pressure \& central corneal thickness amongst hypermetropes \& myopes in adult Indian subjects
}

\author{
Authors \\ Dr Akshay Nayak, Dr Niveditha H, Dr Vishnuvardhan B \\ Department Of Ophthalmology, KIMS Hospital, VV Puram, Bangalore, India \\ Corresponding Author \\ Dr Akshay Nayak
}

Address: 2B Shashi Apartments Model House Street, off KR road, Basavangudi, Bangalore, India-560004

\begin{abstract}
Background: Refractive error are one of the most common ocular disorders. Central corneal thickness (CCT) differs in myopia and hypermetropia, the differences in which can affect the measured Intraocular pressure (IOP).CCT \& IOP also undergo changes with advancing age.

Aim: To measure difference in Intra ocular pressure between myopes and hypermetropes. To measure difference in central corneal thickness between myopes and hypermetropes. To note any variation in CCT and IOP that occurs with advancing age.

Materials \& Methods: This was a prospective study comprising 104 myopic subjects and 136 hypermetropic subjects above age of 40 who went full ophthalmological examination with emphasis on IOP \& CCT.

Results: The intraocular pressure $(\mathrm{mmHg})$ was on the higher side in myopes $(15.090,15.490)$ whereas in hypermetropes $(13.480,13.490)$. Intraocular pressure varies with age. As age advances there is a fluctuation in the measured IOP with a tendency to decrease, a higher IOP $(14.53 \mathrm{mmHg}, 14.61 \mathrm{mmHg})$ was seen from ages 40 to 50 as compared to the other age groups. A thicker cornea was seen in hypermetropes $(0.542 \mathrm{~mm}$, $0.543 \mathrm{~mm})$, while myopes $(0,532 \mathrm{~mm}, 0.537 \mathrm{~mm})$ had a thinner cornea. A very weak correlation between IOP and CCT. ( $r=0.10$ in both eyes for hypermetropes, $r=-0.17,=-0.14$ in myopes). Central corneal thickness was lower $(0.523 \mathrm{~mm}, 0.528 \mathrm{~mm})$ in advanced ages.

Conclusion: IOP was higher in myopes and hence at risk for glaucoma and IOP reduces as age advances. Thicker corneas are seen in hypermetropes leading to falsely high IOP readings and CCT was seen to reduce with age.

Keywords: Central corneal thickness, Intraocular pressure, Hypermetropia, Myopia,
\end{abstract}

\section{Introduction}

Under corrected refractive error is one of the commonest causes of reversible blindness in India. ${ }^{[1]}$ It was noticed that in the urban population in southern India, $42.16 \%$ of the population had refractive errors with a prevalence of $17.8 \%$ and $18.8 \%$ for myopia and hyperopia, respectively, in the age group of $40-$ to $49 .{ }^{[2]}$ Myopia is a form of refractive error where in parallel rays of light come to focus in front of the retina when accommodation is at rest. Hyperopia is a refractive error where parallel rays of light come to focus some distance behind the retina when accommodation is at rest. ${ }^{[3]}$ Corneal rigidity, the measurement of the ability of the cornea to change shape in response to pressure also plays a vital 
role in the accuracy of all tonometers, especially applanation tonometers. ${ }^{[4]}$ It has been noted that ocular rigidity tends to be more in hyperopic eyes and reduced in myopic eyes when compared with emmetropic eyes. Hence, it was suggested that at the very least, a central corneal thickness (CCT) should be obtained by pachymetry for all patients diagnosed as glaucoma suspects (including ones with ocular hypertension) as well as those suffering from normal tension glaucoma(NTG) to get the correct intraocular pressure measurements, and these values should be corrected for the CCT. The general agreement is that the Goldmann applanation tonometer may give a falsely high reading in patients with structurally thicker corneas and falsely lower reading in patients with thinner corneas. ${ }^{[4]}$ Myopic eyes had little higher intra ocular pressure than hyperopic eyes. The relationships between intra ocular pressure and many different factors was investigated, demonstrating that mean IOP levels were associated with refractive status, age, country of birth and interaction between refractive status with country of birth. It was said that there was a complicated relationship between intra ocular pressure and refractive status. ${ }^{[5]}$ Therefore this study will help us understand better the effects of refractive error on key ocular parameters of eye namely intra ocular pressure and central corneal thickness along with variations that come with age.

\section{Materials \& Methods}

This is a comparative clinical study carried for period of 18 months comprising of two groups above 40 years of age. It will comprise of healthy individuals visiting for routine eye check-up and clinically diagnosed as myopia and hypermetropia. It includes 240 Subjects divided into 2 groups: Group A: Myopic subjects>40yrs. Group B: Hypermetropic subjects $>40 y$ rs. Written informed consent is taken from all the subjects. A pre-structured proforma is used to collect the base line data. Detailed ocular clinical examination is done for those who satisfy the inclusion and exclusion criteria. Snellen's chart is used for testing visual acuity, auto refraction is used for refraction testing, ultrasonic pachymetry is used to measure central corneal thickness, perkins applanation tonometer is used to measure intraocular pressure, indirect ophthalmoscopy for fundus evaluation \& slit lamp biomicroscope for evaluation of anterior and posterior segment pathologies.

Inclusion Criteria: GROUP 'A': Men and women of $>40$ yrs of age using myopic correction glasses or having history of short sightedness. GROUP 'B': Men and women of $>40$ yrs of age using hyperopic correction glasses or having history of long sightedness.

Exclusion Criteria: It includes -Emmetropes, subjects with history of ocular infections, ocular trauma, congenital/hereditary ocular disorders, with diabetic and/or hypertensive retinopathy changes, with posterior segment pathologies, subjects with history of any ocular surgery, subjects with macular degeneration due to causes other than refractive errors \& ones who don't have perception of light.

Statistical Analysis Used: Chi square test, Student ' $t$ ' test, Mean, Proportion, Standard Deviation, ANOVA test \& Pearson Correlation test.

\section{Results}

In this study there were 136 hypermetropes as compared to 104 myopes with a mean age of 50.2 $(+/-7.1 \mathrm{SD})$ and the ages were in the range of 40 to 76 years. $61.7 \%$ of the study patients were found to be in the age group of 40-50 years, 31.3 $\%$ in the 51-60 age group and the least, $7.1 \%$, in the $>60$ age group. Majority of the Hypermetropes (57.4\%) and Myopes (67.3\%) belonged to the age group of 40-50 years. Among the two groups, a higher percentage of hyperopic refractive error was seen in the 51-60 age group whereas higher percentage of myopes were in the 40-50 and >60 age groups. There was no significant age difference between the age groups, $\mathrm{p}=0.10$. 
The sex ratio amongst hypermetropes was 1.3:1 with a slight male preponderance (77 males and 59 females) and in myopes was 1:1 with an equal distribution of males and females(52 males and 52 females).There was no significant difference between the two groups, $\mathrm{p}=0.31$.
Mean refractive error in hypermetropes was +1.95 in the right and +1.80 in the left eye, whereas it was -2.48 and -2.12 in the right and left eyes of myopes respectively. The degree of error was more in the myopic group and was found statistically significant with $\mathrm{p}<0.05$, as per student paired $t$ test.

Table 1: Comparison of mean Central Corneal Thickness of right \& left eye between Hypermetropes \& Myopes

\begin{tabular}{|l|c|c|c|c|} 
Side & Groups & $\mathrm{N}$ & Mean $(\mathrm{mm})$ & $\mathrm{SD}$ \\
\hline Right Eye & Hypermetropes & 136 & 0.542 & 0.020 \\
\cline { 2 - 5 } & Myopes & 104 & 0.532 & 0.021 \\
\hline \multirow{3}{*}{ Left Eye } & Hypermetropes & 136 & 0.543 & 0.019 \\
\cline { 2 - 5 } & Myopes & 104 & 0.537 & 0.020 \\
& & & & \\
\hline
\end{tabular}

Table 2: Comparison of mean Intraocular Pressure in right \& left eye between Hypermetropes and Myopes

\begin{tabular}{|l|c|c|c|c|c|} 
Side & Groups & $\mathrm{N}$ & Mean $(\mathrm{mmHg})$ & SD & Mean Diff \\
\hline Right Eye & Hypermetropes & 136 & 13.480 & 3.300 & \multirow{2}{*}{-1.610} \\
\cline { 2 - 5 } & Myopes & 104 & 15.090 & 3.414 & \\
\hline \multirow{2}{*}{ Left Eye } & Hypermetropes & 136 & 13.490 & 3.086 & \multirow{2}{*}{-2.000} \\
\cline { 2 - 5 } & Myopes & 104 & 15.490 & 2.913 & \\
\hline
\end{tabular}

Figure 1: Graphical representation of mean $\mathrm{IOP}(\mathrm{mmHg})$ of right \& left eye between Hypermetropes \& Myopes

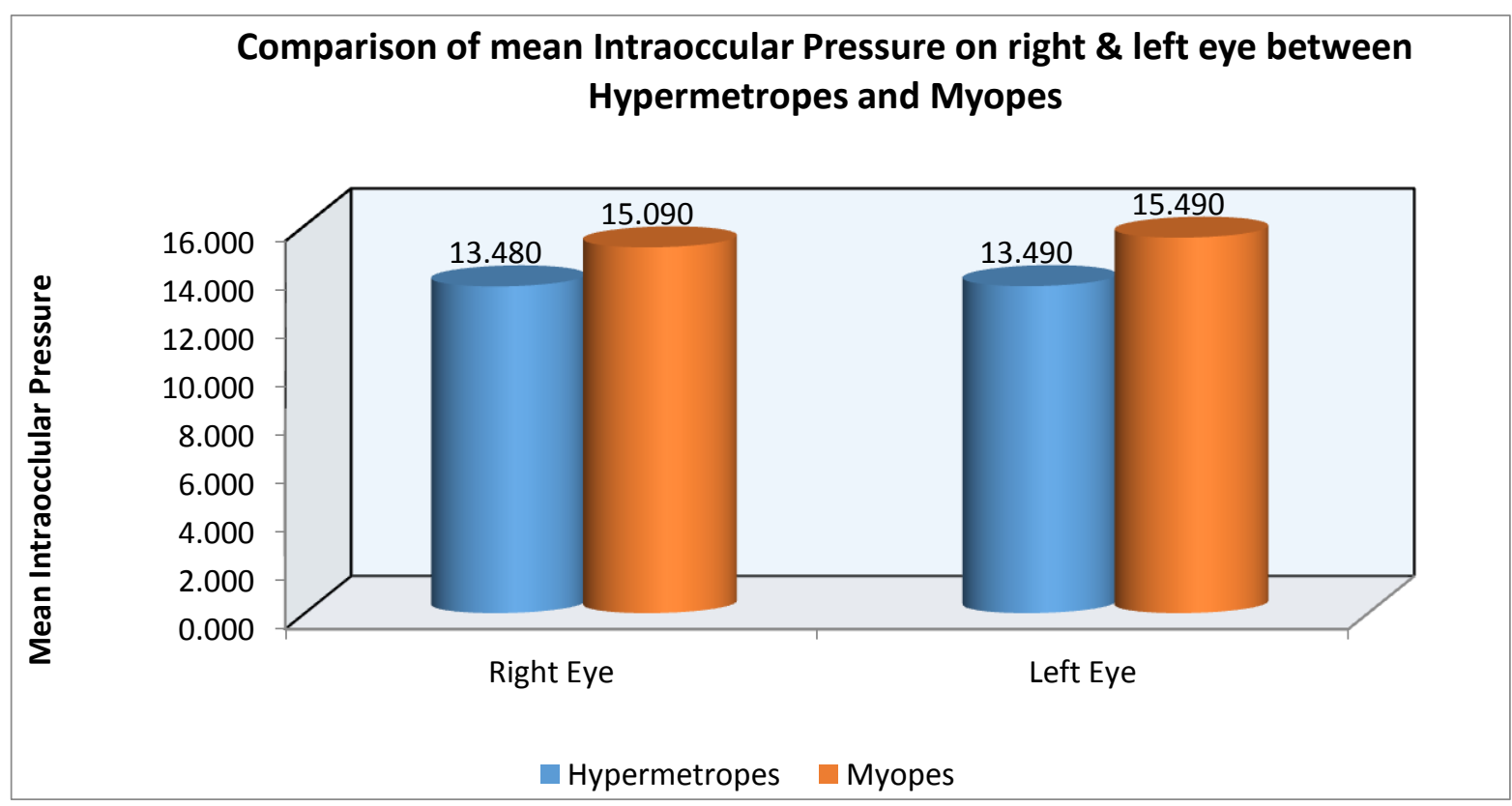

Table 3: Comparison of mean Central Corneal Thickness on right \& left eye between different age groups

\begin{tabular}{|l|c|c|c|c|} 
Side & Age Group & $\mathrm{N}$ & Mean $(\mathrm{mm})$ & $\mathrm{SD}$ \\
\hline Right Eye & $40-50 \mathrm{yrs}$ & 148 & 0.540 & 0.021 \\
\cline { 2 - 5 } & $51-60 \mathrm{yrs}$ & 75 & 0.537 & 0.021 \\
\cline { 2 - 5 } & $>60 \mathrm{yrs}$ & 17 & 0.523 & 0.013 \\
\hline Left Eye & $40-50 \mathrm{yrs}$ & 148 & 0.543 & 0.019 \\
\cline { 2 - 5 } & $51-60 \mathrm{yrs}$ & 75 & 0.538 & 0.020 \\
\cline { 2 - 5 } & $>60 \mathrm{yrs}$ & 17 & 0.528 & 0.014 \\
\hline
\end{tabular}


Figure 2: Graphical representation of mean CCT of right \& left eye between different age groups

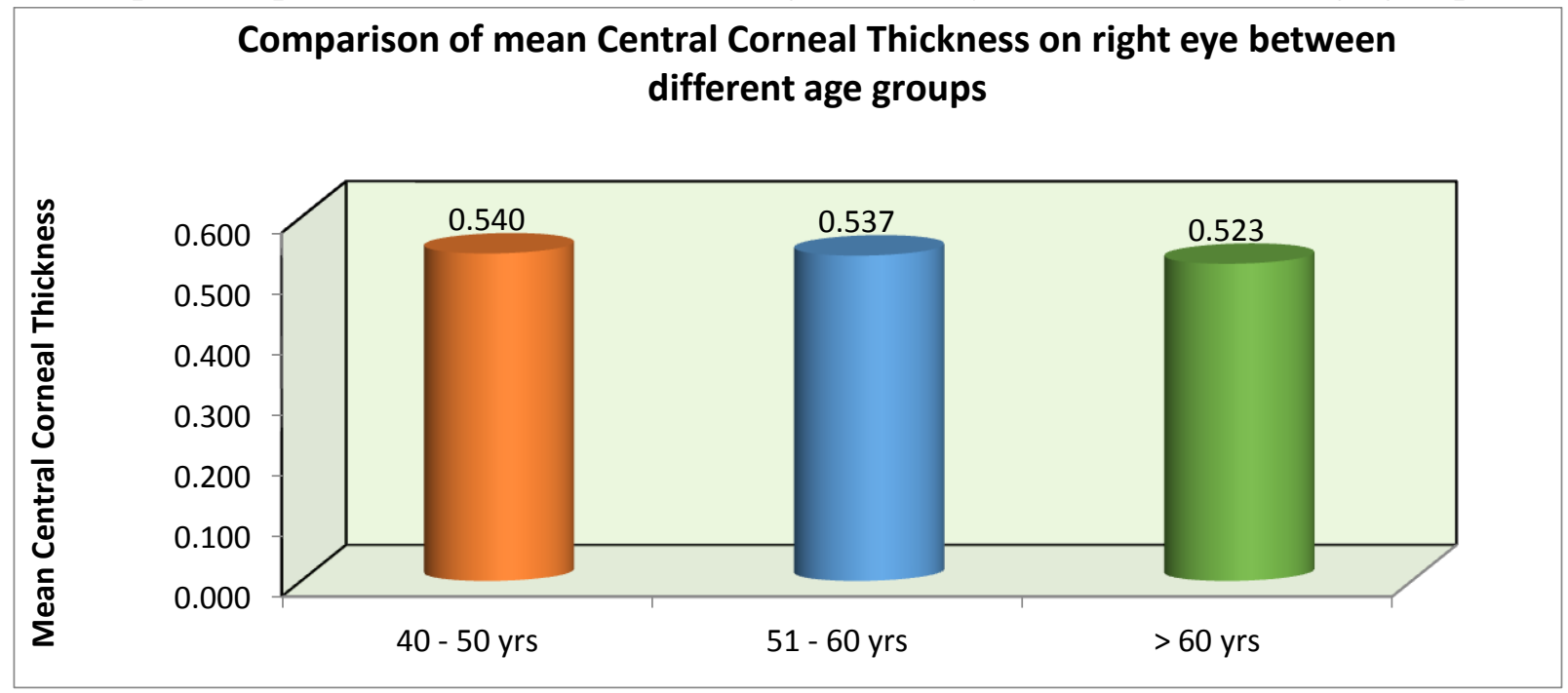

Table 4: Comparison of mean Intra Ocular Pressure based on the age of the study patients

\begin{tabular}{|c|c|c|c|c|c|}
\hline \multicolumn{6}{|c|}{$\begin{array}{l}\text { Comparison of mean Intra Ocular Pressure based on the age of the } \\
\text { study patients on Right \& left side eye }\end{array}$} \\
\hline \multirow[b]{2}{*}{ Age Group } & \multirow[b]{2}{*}{$\mathrm{N}$} & \multicolumn{2}{|c|}{ Right Eye } & \multicolumn{2}{|c|}{ Left Eye } \\
\hline & & $\begin{array}{c}\text { Mean } \\
(\mathrm{mmHg})\end{array}$ & SD & $\begin{array}{c}\text { Mean } \\
(\mathrm{mmHg})\end{array}$ & SD \\
\hline $40-50 \mathrm{yrs}$ & 148 & 14.53 & 3.67 & 14.61 & 3.08 \\
\hline $51-60 \mathrm{yrs}$ & 75 & 13.73 & 2.98 & 13.93 & 3.29 \\
\hline$>60 \mathrm{yrs}$ & 17 & 13.06 & 2.82 & 14.06 & 3.36 \\
\hline
\end{tabular}

Figure 3: Scatter plots showing relationships between IOP and CCT in refractive errors Strength of correlation

0.01 - 0.20 - Very Weak Correlation

0.21 - 0.40 - Weak Correlation

0.41 - 0.60 - Moderate Correlation

0.61 - 0.80 Strong Correlation

0.81 - 1.00 - Very Strong Correlation

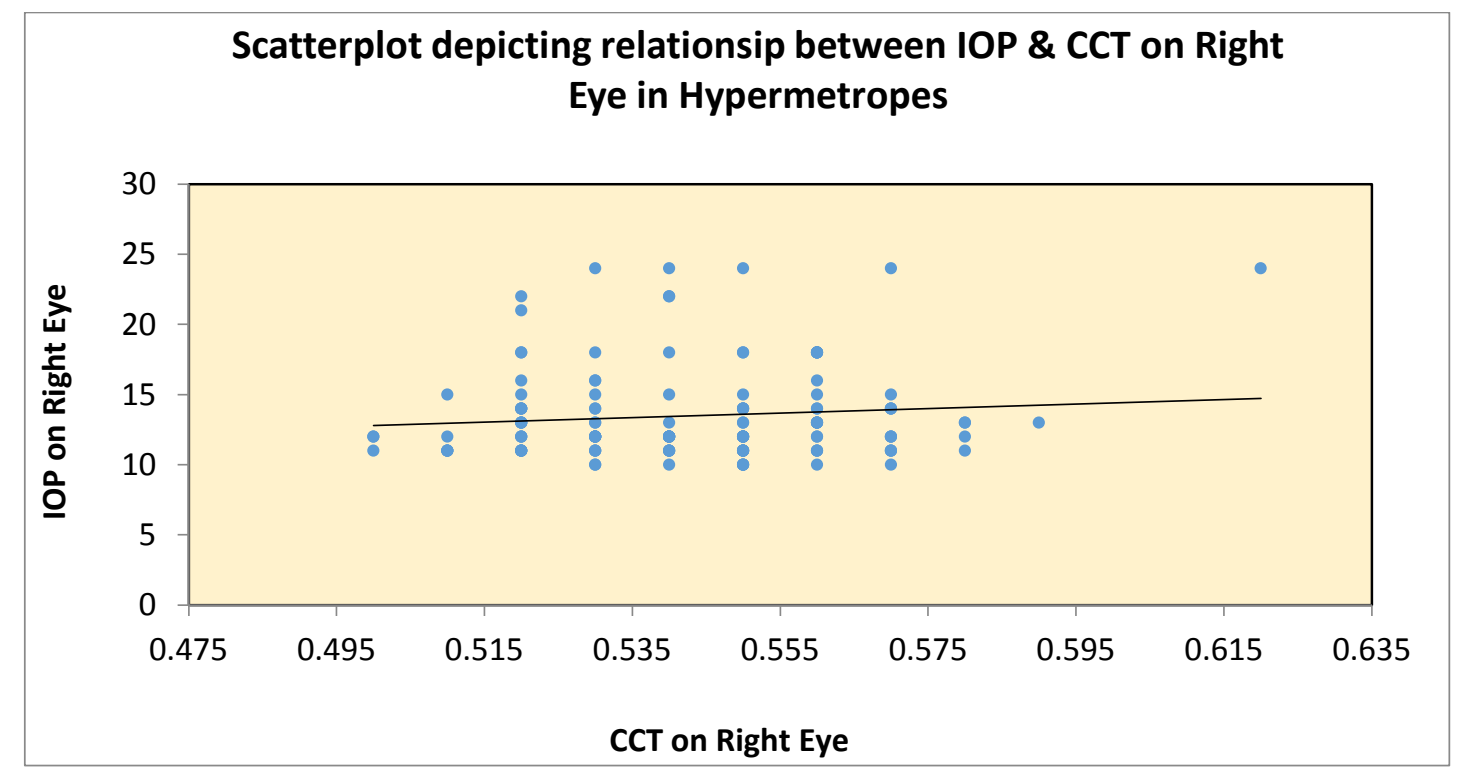



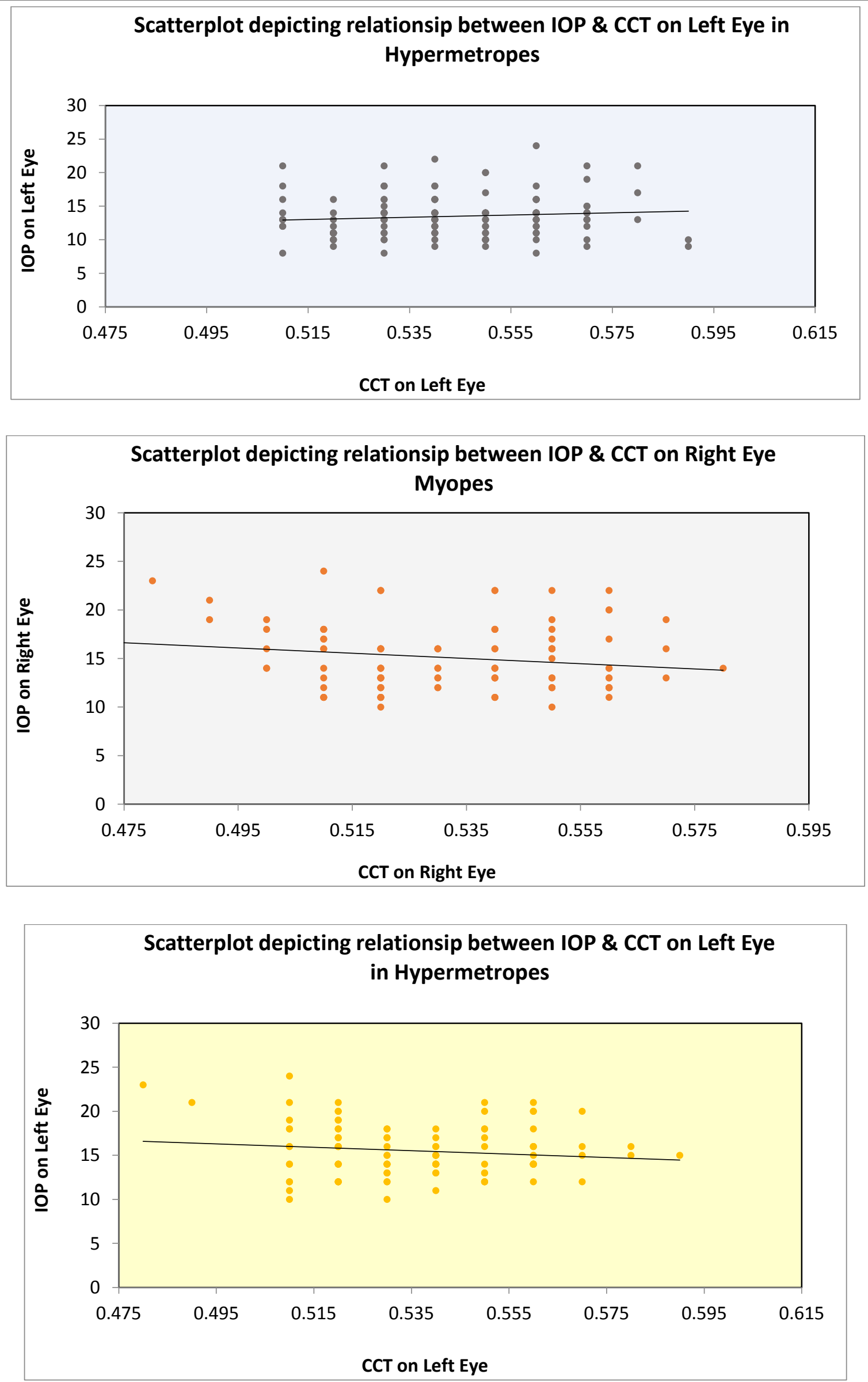


\section{Discussion}

Refractive errors are the commonest eye conditions. In urban India it is reported that 49.3 million of those aged $\geq 15$ years may have refractive errors. Not a lot is known about the true relationship between refractive status and IOP when the central corneal thickness (CCT) is considered, as the CCT has a significant influence on IOP measurement. This was a comparative study of IOP and CCT between adult hypermetropic and myopic patients.

In our study, most of the hypermetropes (57.4\%) and myopes $(61.7 \%)$ belonged to the age group of 40-50 years. Among the hypermetropics, higher percentage of hyperopic refractive error was seen in the age group of 51-60 whereas myopics were more in the 40-50 and >60 age groups. Dandona et al studied an urban population in southern India and reported that $42.16 \%$ of the population had errors of refraction with a prevalence of $17.8 \%$ and $18.8 \%$ for myopic error and hyperopic error, respectively, in the 40- to 49-year group, $29.6 \%$ and $39.6 \%$ in the 50- to 59-year group, $44.8 \%$ and $29.7 \%$ in the 60 - to 69 -year group, and $50 \%$ and $30.4 \%$ in the $>70$-year group. ${ }^{[2]}$

In our study the central corneal thickness (CCT) was greater in hypermetropes, $0.542 \mathrm{~mm}$ and 0.543 , with an average of $0.5425 \mathrm{~mm}$ whereas myopes had lower values of CCT, $0.532 \mathrm{~mm}$ and $0.537 \mathrm{~mm}$, with an average of $0.5345 \mathrm{~mm}$. There was a statistically significant difference between the groups with $\mathrm{p}<0.001$ with respect to right eye, and $\mathrm{p}<0.008$ with respect to left eye, overall $p<0.05$ as per independent student ' $t$ ' test. There were contrasting results in various studies. A study by Lekskul et al, where 467 participants were enrolled and refractive error was measured, 186 (39.8\%) were males and $281(60.2 \%)$ were females. It was noted that the average CCT was 535.2 +/- 29.9 micron. The mean CCT of right and left eyes were $535.3+/-30.4$ micron, and $535.1+/-29.5$ micron, respectively and inferred no correlation with refractive errors. ${ }^{[6]}$ Chang et al reported that the cornea were thinner in myopic eyes in 216 young adults with an average refractive error of -4.17 diopters, ${ }^{[7]}$ while Fam et al found that CCT was having no correlation with the degree of myopia in a study of 714 Singaporean Chinese with a mean refractive error of -5.3 diopters. ${ }^{[8]}$

In this study, the mean CCT (mm) was seen to reduce with advancing age, highest being in 40-50 age group $(0.540,0.543)$ and lowest in $>60$ year group $(0.523,0.528)$. The difference between the three groups was found to be statistically significant with $\mathrm{p}<0.05$ as per ANOVA test and our findings are in line with most of the earlier studies. Cho et al found a negative correlation between age and CCT, although this was mainly due to female subjects only; no significant correlation between age and CCT was found in the males. ${ }^{[9]}$ Olsen and Ehlers studied subjects, aged 10-90 yrs, and found a significant negative correlation between CCT \& age. ${ }^{[10]}$ In this study, the Correlation of IOP and CCT was positive , but a very weak correlation $(r=0.10,0.10)$ among the hypermetropes. The Correlation of IOP and CCT was negative, and also very weak $(\mathrm{r}=-0.17,-0.14)$ among the myopes. This is accordance with thicker corneas giving a higher IOP and vice versa when using a Goldmanns tonometer. The relation in our case was weak perhaps due to effect of age on the measured IOP in older subjects. Cho et al inferred a statistically significant positive correlation between CCT and IOP, and true for both male and female subject. No statistically significant difference was noted in intraocular pressures between male and female subjects ${ }^{\left[{ }^{[9]}\right.}$ Swann et al. measured the IOP and CCT of 50 Caucasian and 50 Chinese subjects, aged 17-23 yrs, and they suggested a significant correlation between CCT and IOP for both groups. ${ }^{[11]}$

In our study the average IOP in hypermetropes was on the lower side, being 13.480 and 13.490 in the right and left eye respectively, while the average IOP in myopes was 15.090 and 15.490 in the right and left eye respectively. There was a statistically significant difference between the two groups with $\mathrm{p}<0.001$ as per independent student $\mathrm{t}$ test. Nomura et al in a study which had a mean 
age of $58.9+/-10.9$ demonstrated that the mean IOP value of the moderate myopia group was considerably higher than those of the hyperopia ( $\mathrm{p}$ $<0.0001$ ), emmetropia ( $\mathrm{p}<0.0001$ ), or mild myopia (p 1/4 0.004) groups and average IOP value of the mild myopics was also significantly higher than that of the hyperopic group. They also noted a mean IOP of $13+/-2.6$ and a mean CCT of 0.516 $\mathrm{mm}+/-0.033 \mathrm{~mm}^{[12]}$ In our study the mean IOP was highest (Mean 14.53, 16.61 $\mathrm{mm} \mathrm{Hg}$ ) in age 40-50.The mean IOP was lowest in the age group $>60$ with respect to right eye(Mean $13.06 \mathrm{~mm}$ $\mathrm{Hg}$ ), whereas in age group 51-60 with respect to left eye(Mean $13.93 \mathrm{~mm} \mathrm{Hg}$ ). The difference over the age groups however was not significant and thus not strongly related. Previous studies have demonstrated variable associations. A Japanese study on 2,00,000 subjects covering all adult ages, using Schiotz or non-contact tonometry, it demonstrated decreasing IOP with increasing age, and the trend persisted even after adjustment for both systolic blood pressure and BMI. ${ }^{[13]}$ The Framingham Eye Study demonstrated a trend for increasing IOP up to age 74 years, but not at higher ages. ${ }^{[14]}$

\section{Conclusion}

IOP readings were higher in myopes as compared to hypermetropes, hence predisposed to glaucomatous changes especially primary open angle glaucoma. IOP was higher in the relatively younger ages and demonstrated variations as age advanced with a tendency to decrease. Hypermetropes were found to have thicker corneas in comparison to myopes. The CCT was seen to reduce at advanced ages irrespective of refractive error. IOP and CCT have very weak correlation with each other irrespective of refractive error.

\section{References}

1. Raju P, V Ramesh S, Arvind H, George R, Baskaran M, Paul P et al. Prevalence of Refractive Errors in a Rural South Indian
Population. Investigative Ophthalmology\& Visual Science. 2004;45(12):4268.

2. Dandona L, Dandona R, Naduvilath TJ, et al. Refractive errors in an urban population in Southern India: the Andhra Pradesh Eye Disease Study. Invest Ophthalmol Vis Sci. 1999;40:2810-2818.

3. Abrams Duke-Elder S. Duke-Elder's practice of refraction. 10th ed. Wobum,MA[u.a.]: Elseveir; 1993.

4. Damji K, Muni R, Munger R. Influence of Corneal Variables on Accuracy of Intraocular Pressure Measurement. Journal of Glaucoma. 2003;12(1):69-80.

5. David R, Zangwill LM, Tessler Z, Yassur Y. The correlation between intraocular pressure and refractive status. Archives of Ophthalmology. 1985 Dec 1;103(12):1812-5.

6. Lekskul M, Aimpun P, Nawanopparatskul B, Bumrungsawat S, Trakulmungkijkarn $\mathrm{T}$, Charoenvanichvisit $\mathbf{J}$ et al. The correlations between Central Corneal Thickness and age, gender, intraocular pressure and refractive error of aged 12-60 years old in rural Thai community,Journal of the Medical Association of Thailand 2005, 88 Suppl 3:S175-9

7. Chang SW, Tsai IL, Hu FR, Lin LL, Shih YF. The cornea in young myopic adults. Br J Ophthalmol 2001;85:961-70.

8. Fam HB, How AC, Baskaran M, Lim KY, Chan YH, Aung T. Central corneal thickness and its relationship to myopia in Chinese adults. Br J Ophthalmol 2006;90:1451-3.

9. Cho P, Lam C. Factors affecting the central corneal thicknessof Hong Kong Chinese. Curr Eye Res 1999;18:368-74.

10. Olsen T, Ehlers N. The thickness of the human cornea as determined by a specular method. ActaOphthalmol. 1984;62:859-871.

11. Swann PG, Yap M, Wong E, Bohl T, Bowen $\mathrm{K}$, Gaffney J. Intraocular pressure measurements and corneal centre thickness in Chinese and Caucasian populations. Proceedings of the Ninth Asian-Pacific 
Optometric Congress. Hong Kong. 1993:6669.

12. Nomura H, Ando F, Niino N, Shimokata H, Miyake Y. The relationship between intraocular pressure and refractive error adjusting for age and central corneal thickness. Ophthalmic and Physiological Optics. 2004 Jan;24(1):41-5.

13. Shiose Y. The Aging Effect on Intraocular Pressure in an Apparently Normal Population. Archives of Ophthalmology. 1984;102(6):883-887.

14. Harold A. Howard M. Leibowitz James P. Ganley Mohandas M. Kini Theodore Colton Rita S The Framingham Eye Study: I. Outline And Major Prevalence Findings American Journal Of Epidemiology, Volume 106, Issue 1, 1 July 1977, Pages 17-32. 